\title{
PERANCANGAN SISTEM INFORMASI AKUNTANSI PENGGAJIAN BERBASIS WEB PADA LAUNDRY SEPATU SNEAKLIN BANDUNG
}

\begin{abstract}
The purpose of this research is to design an accounting information system application that processes webbased salary data on Sneaklin Bandung laundry shoes, the method is done using descriptive and experimental methods. Salary data processing performed at Sneaklin Bandung Laundry Shoe is already using a computer, namely using the Microsoft Excel program, this method is still troublesome administrative staff in managing employee salary calculation, employee data, and payroll processes. The design of a web-based payroll accounting information system in Sneaklin Bandung shoe laundry using the PHP and MySQL programming languages is expected to facilitate administrative staff in processing payroll data and managing employee data.
\end{abstract}

\begin{abstract}
ABSTRAK: Tujuan dari penelitian ini adalah untuk merancang sebuah aplikasi sistem informasi akuntansi yang mengolah data gaji berbasis web pada laundry sepatu sneaklin Bandung, metode yang dilakukan menggunakan metode deskriptif dan eksperimen. Pengolahan data gaji yang dilakukan di Laundry Sepatu Sneaklin Bandung ini sudah menggunakan komputer, yaitu menggunakan program Microsoft Excel, cara ini masih merepotkan staf administrasi dalam mengelola perhitungan gaji karyawan, data karyawan dan proses penggajian. Perancangan sistem informasi akuntansi penggajian berbasis web pada laundry sepatu sneaklin bandung menggunakan Bahasa pemrograman PHP dan MySQL ini diharapkan dapat mempermudah staf administrasi dalam mengolah data penggajian dan mengelola data karyawan.
\end{abstract}

\section{Rida Annurfaida}

Komputerisasi Akuntansi, Fakultas Teknik dan Ilmu Komputer, Universitas

Komputer Indonesia

Jl. Dipatiukur No. 112-116, Lebakgede, Kec. Coblong, Kota Bandung, Indonesia

Keywords: Information Systems, Accounting

Kata Kunci:

Sistem Informasi,

Akuntansi, Penggajian

\section{Pendahuluan}

Perkembangan teknologi serta kemajuan yang sangat pesat, mendorong kita untuk beradaptasi mengikuti perkembangan teknologi yang ada. Berbagai sarana disiapkan untuk memberikan informasi yang akurat tentang suatu kondisi atau masalah yang terjadi. Hal ini dimaksud agar mempercepat proses kegiatan dalam memasukan data ataupun menghasilkan data yang dibutuhkan, agar pekerjaan yang dilakukan lebih efisien dan efektif.

Gaji merupakan sejumlah uang yang diberikan kepada seorang pegawai atau karyawan sebagai imbalan atas usaha atau kerja yang telah dilakukan terhadap perusahaan. Dalam pemberian gaji setiap perusahaan memiliki sistem yang berbeda. Penggajian salah satu hal yang terpenting bagi suatu perusahaan karena merupakan faktor yang menentukan kinerja karyawan dan penggajian karyawan di perusahaan, penggajian bagian yang harus diperhatikan karena dalam sistem penggajian, karyawan sangat sensitif mengenai data laporan penggajian atau hal-hal yang tidak wajar dan diinginkan mengenai penggajian yang biasa dilakukan diakhir bulan. 
Untuk mudah mengakurasikannya proses penggajian disarankan agar perusahaan menerapkan sistem informasi yang terkomputerisasi. Perancangan Sistem Informasi Akuntansi Penggajian merupakan faktor yang menentukan bagaimana kinerja karyawan di perusahaan, dalam pembayaran gaji atau upah secara langsung kepada karyawan diperusahaan, dengan menggunakan PHP dan database MySQL karena dengan menggunakan sistem informasi akuntansi dan program website dapat membantu dalam pembuatan data laporan keuangan pada perusahaan.

Sistem penggajian harus diterapkan secara efektif dan efisien agar tidak terjadi kekeliruan dalam penggajian kepada para karyawan. Bagan alur yang digunakan berupa flowchart, Use Case dan ERD diperlukan untuk membantu dalam perancangan sistem informasi akuntansi penggajian.

Berdasarkan latar belakang diatas, penelitian ini bertujuan untuk merancang sistem informasi akuntansi penggajian menjadi terkomputerisasi. Penulis mencoba untuk membuat artikel dengan judul "Perancangan Sistem Informasi Akuntansi Penggajian."

\section{Metode}

Dalam penelitian ini, penulis menggunakan pendekatan penelitian deskriptif dan eksperimen. Untuk melakukan penelitian dan menemukan masalah yang ada di perusahaan, penulis memerlukan metode penelitian yang dapat membantu penulis dalam melakukan penelitian di perusahaan.

Menurut Sugiyono definisi metode penelitian deskripsi adalah sebagai berikut:

"Penelitian yang dilakukan untuk mengetahui keberadaan nilai variabel mandiri, baik satu variable atau lebih (independen) tanpa membuat perbandingan atau menghubungkan dengan variable lain”.[1]

Definisi metode penelitian eksperimen menurut Syaiful Bahri Djamarah dalam bukunya yang berjudul Strategi Belajar adalah sebagai berikut: "Cara penyajian pelajaran, dimana peserta didik melakukan percobaan dengan mengalami dan membuktikan sendiri sesuatu yang diperlajari."

Dari uraian di atas penulis menyimpulkan bahwa metode penelitian deskriptif dan metode penelitian eksperimen yaitu metode yang digunakan untuk melakukan penelitian dan percobaan dengan mengalami dan membuktikan sendiri sesuatu yang dipelajari baik satu variable atau lebih, tanpa membuat perbandingan atau menghubungkan dengan variable lainnya. Hipotesis

Kerangka Teoritis Dan Pengembangan

\section{Perancangan}

Perancangan menurut Al-Bahri bin Landjamudin menyebutkan bahwa: "Perancangan adalah kegiatan yang memiliki tujuan dan kemampuan untuk membuat beberapa alternative pemecahan masalah yang ada".[2]

\section{Sistem}

Definisi sistem menurut Azhar Susanto menjelaskan bahwa: "Sistem adalah kumpulan dari sub sistem bagian komponen apapun baik phisik ataupun non phisik yang saling berhubungan satu sama lain dan bekerja sama secara harmonis untuk mencapai tujuan tertentu”.'[3]

\section{Informasi}

Menurut Krismiaji: "Informasi adalah data yang telah diorganisasi dan telah memiliki kegunaan dan manfaat".[4]

Sedangkan menurut Jogiyanto mendefinisikan bahwa: "Informasi adalah data yang diolah menjadi bentuk data yang memberikan arti dan manfaat bagi yang menerimanya".[5] 
Berdasarkan definisi diatas penulis dapat menyimpulkan bahwa informasi adalah data yang diorganisasi dan memberi manfaat bagi penerimanya.

\section{Sistem Informasi}

Menurut Azhar Susanto: "Kumpulan dari sub-sub sistem baik phisik maupun non phisik yang saling berhubungan satu sama lain dan bekerja sama secara harmonis untuk satu tujuan yaitu mengelola dan menjadi informasi yang bermanfaat dan berguna.’'[6]

\section{Akuntansi}

Menurut Soemarso: "Akuntansi merupakan Proses pengidentifikasian, mengukur, melaporkan informasi ekonomi, untuk memungkinkan adanya penilaian dan keputusan yang jelas dan tegas bagi mereka yang menggunakan informasi tersebut".[7]

Sedangkan definisi menurut Azhar Susanto menyebutkan bahwa: "Akuntansi adalah Bahasa bisnis setiap organisasi menggunakan sebagai Bahasa komunikasi saat berbisnis".[8]

Berdasarkan definisi di atas dapat disimpulkan bahwa akuntansi adalah bahasa bisnis yang digunakan sebagai bahasa komunikasi dalam memproses pengidentifikasian, laporan informasi, dan mengukur untuk memungkinkan adanya keputusan dan penilaian dengan jelas dan tegas bagi yang menggunakan informasi tersebut.

\section{Sistem Akuntansi}

Menurut Warren "Sistem akuntansi adalah metode untuk mengumpulkan, mengelompokkan, merangkum serta melaporkan informasi keuangan dan operasi perusahaan".[9]

\section{Sistem Informasi Akuntansi}

Menurut Krismiaji menjelaskan bahwa: "Sistem informasi akuntansi adalah sebuah sistem yang memproses data dan transaksi guna menghasilkan informasi yang bermanfaat untuk merencanakan, mengendalikan dan memproses bisnis".[10]

Definisi menurut Sri Dewi Anggadini menjelaskan bahwa sistem informasi akuntansi adalah sebagai berikut: "Sistem Informasi Akuntansi yaitu suatu sistem yang berfungsi untuk mengorganisasi formulir, catatan dan laporan yang dikoordinasi untuk menghasilkan informasi keuangan yang dibutuhkan dalam pembuatan keputusan manajemen dan pimpinan perusahaan dan dapat memudahkan pengelolaan perusahaan".[11]

Berdasarkan dari definisi sistem informasi akuntansi adalah sistem yang berfungsi untuk mengorganisasi atau memproses catatan, formulir, data, dan laporan yang dikoordinasi guna menghasilkan informasi yang bermanfaat untuk mengendalikan dan memproses data yang dibutuhkan dalam pembuatan keputusan dan pimpinan dalam mengolah data perusahaan.

\section{Gaji}

Menurut Soemarso "Gaji merupakan imbalan kepada pegawai yang diberi tugas-tugas administrative dan pimpinan yang jumlahnya biasanya tetap secara bulan/tahun".[12]

Menurut Mulyadi menjelaskan bahwa gaji adalah sebagau berikut: "Gaji merupakan pembayaran atas penyerahan jasa yang dilakukan oleh karyawan yang mempunyai jenjang jabatan manajer”.[13]

Simpulan dari definisi di atas bahwa gaji merupakan pembayaran jasa yang telah dilakukan oleh karyawan atau imbalan kepada pegawai yang diberi tugas dan diberi secara tetap setiap bulan/tahun”.

\section{Upah}

Definisi upah menurut Soemarso adalah sebagai berikut: "Upah merupakan imbalan kepada buruh yang melakukan pekerjaan kasar dan lebih banyak mengandalkan kekuatan phisik dan biasanya jumlah upah ditetapkan secara harian dalam masa kerja".[14]

Menurut Mulyadi, adalah sebagai berikut: 
"Upah merupakan pembayaran atas penyerahan jasa yang dilakukan oleh karyawan pelaksana".[15]

Berdasarkan dari pengertian di atas penulis dapat menyimpulkan bahwa upah adalah kompensasi harian untuk para karyawan atau buruh yang melakukan pekerjaan kasar atau penyerahan jasa yang mengandalkan kekuatan jasmani dalam masa kerjanya.

\section{Hasil dan Pembahasan}

Perancangan sistem yang diusulkan

\subsection{Use Case}

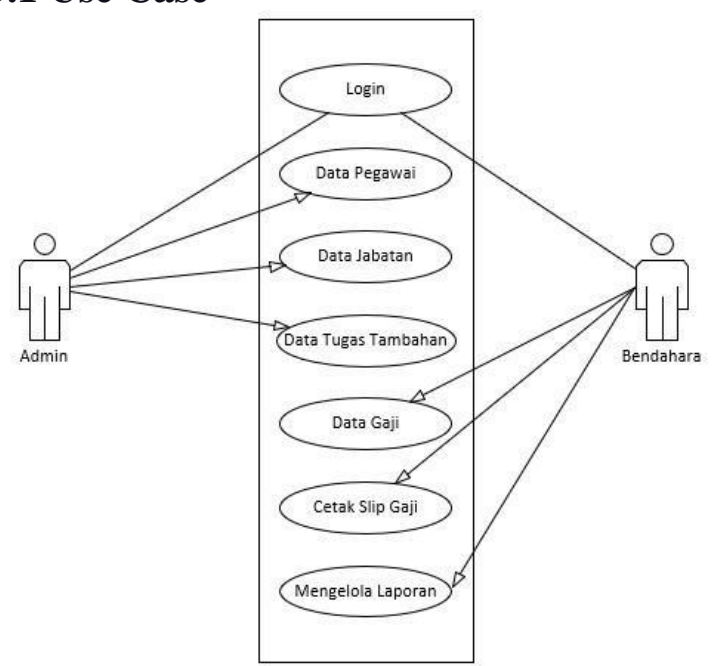

Gambar 1. Use Case

\subsection{Flowchart}

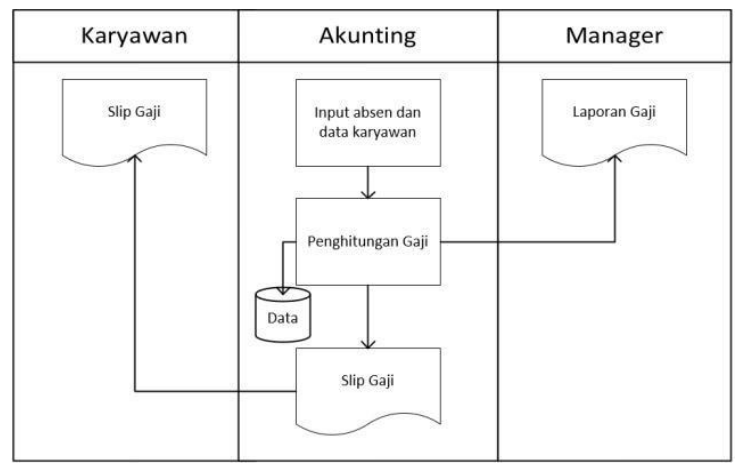

Gambar 2. Flowchart

\subsection{ERD (entity Relationship Diagram)}

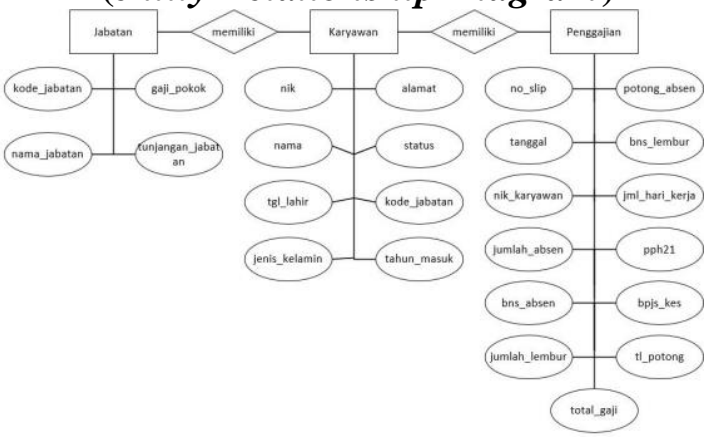

Gambar 3. Entity Relationship Diagram

\subsection{Desain Sistem}

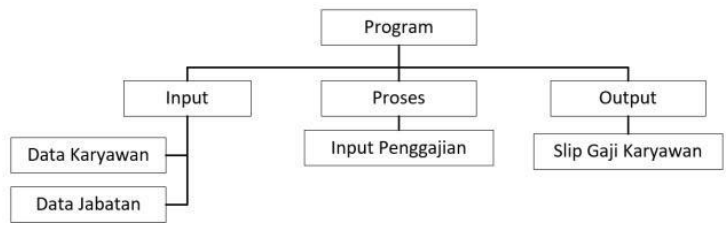

Gambar 4. Desain Sistem

\subsection{Rancangan Struktur Menu}

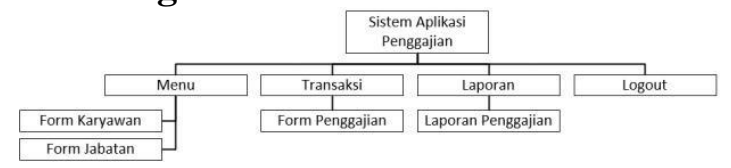

Gambar 5. Rancangan Struktur Menu

\subsection{User Interface}

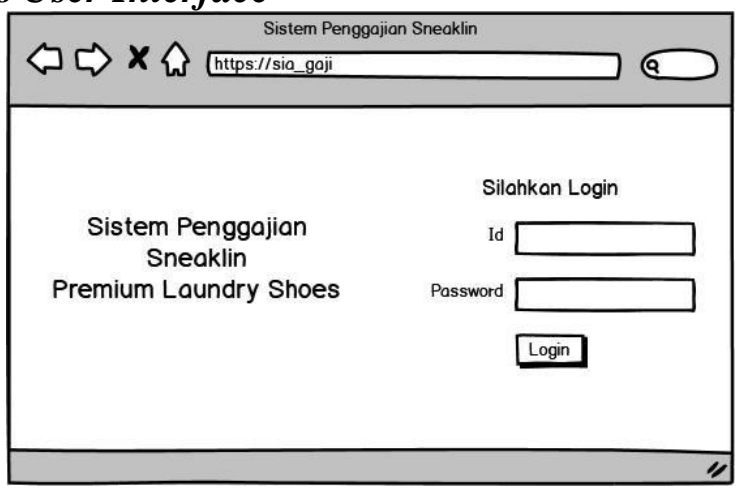

Gambar 6.1 Welcome Page

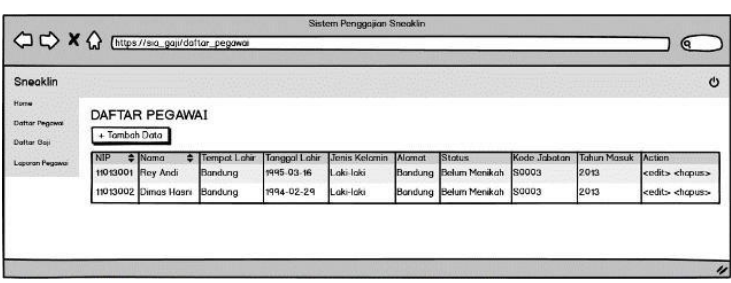

Gambar 6.2 Halaman Daftar Pegawai 


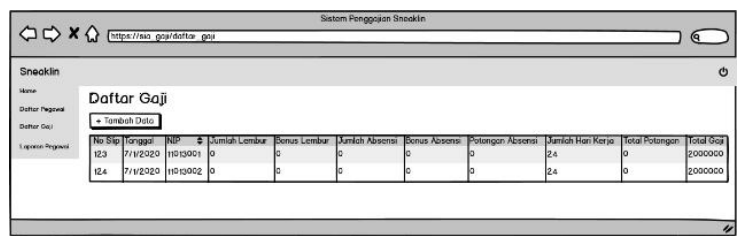

Gambar 6.3 Halaman Daftar Gaji

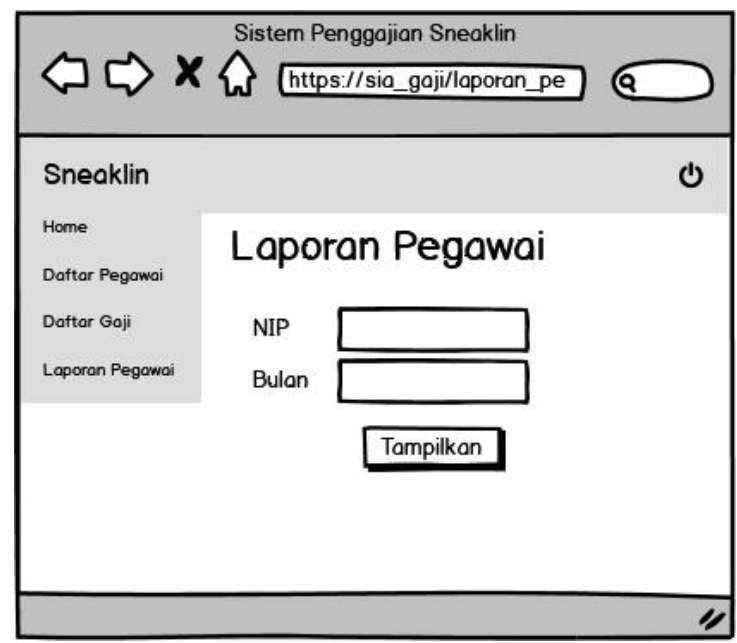

Gambar 6.4 Halaman Laporan Pegawai

\section{Kesimpulan}

Simpulan:

Proses mengolah penggajian karyawan masih belum terkomputerisasi dengan baik. Penulis membuat perancangan sistem informasi penggajian berbasis web dengan menggunakan PHP dan MySQL sebagai database. Diharapkan dengan adanya aplikasi ini dapat membantu staf administrasi untuk mengolah data pegawai dan data penggajian dengan lebih mudah. Aplikasi perancangan sistem informasi akuntansi penggajian ini dapat dikembangkan lebih baik dari ini dan bisa dibuatkan aplikasi yang berbasis android.

\section{Daftar Pustaka}

Sugiyono, Dr. 2010. Metode Penelitian Pendidikan Pendekatan Kuantitatif, Kualitatid dan $R \& D$. ALFABETA.

Al-Bahri bin Landjamudin. 2005. Analisis dan Desain Sistem Informasi, Graha

Ilmu, Yogyakarta.

Azhar Susanto. 2013. Sistem Informasi

Akuntansi. Bandung: Lingga Jaya.

Krismiaji. 2005. Sistem Informasi Akuntansi.
Yogyakarta: Penerbit dan Percetakan AMP YKPN.

L. Bin and Al-Bahra. 2005. Analisis dan Desain Sistem Informasi. Yogyakarta: Graha Ilmu.

Azhar Susanto. 2013. Sistem Informasi Akuntansi Konsep dan Pengembangan. Bandung: Lingga Jaya.

S R, Soemarso. 2009. Akuntansi Suatu Pengantar. Jakarta: Salemba Empat.

Azhar Susanto. 2013. Sistem Informasi Akuntansi. Bandung: Lingga Jaya.

Carl S. Warren, dkk. 2014. Accounting Indonesial Adaptation. Jakarta: Salemba Empat.

Krismiaji. Sistem Informasi Akuntansi. Yogyakarta: Penerbit Unit Penerbit dan Percetakan AMP YKPN, 2005.

Puspitawati, Lilis., Sri Dewi Anggadini. 2011. Sistem Informasi Akuntansi. Yogyakarta: Graha Ilmu.

S R, Soemarso. 2009. Akuntansi Suatu Pengantar. Jakarta: Salemba Empat.Mulyadi. 2010. Sistem Akuntansi. Jakarta: Salemba Empat.

S R, Soemarso. 2009. Akuntansi Suatu Pengantar. Jakarta: Salemba Empat. berkualitas. 